\title{
¡Para lo que alcance! El gasto doméstico de trabajadoras en la Ciudad de México, 1917-1921
}

\author{
Fernando Vialli Ávila Campos \\ Instituto de Investigaciones Dr. José María Luis Mora \\ favila@institutomora.edu.mx
}

\begin{abstract}
Resumen: En el siguiente artículo se estudia el gasto doméstico de una costurera que confeccionaba ropa a domicilio y una mujer que elaboraba tortillas diariamente. El objetivo de este tex to es conocer las condiciones de vida de estas trabajadoras después de la Revolución mexicana para saber cómo impactó este proceso armado en sus hogares. Para saberlo, se tomó en cuenta la conformación de sus canastas básicas a partir de la relación existente entre sus ingresos y los precios de los productos de primera necesidad como el alimento, alquiler, vestimenta, combustibles y aseo. Este estudio se realizó a partir de las encuestas sobre el costo de la vida obrera, elaboradas por el Departamento del Trabajo durante 1921. Cabe mencionar que a partir de esta herramienta contable se observó que las trabajadoras subsistían con presupuestos limitados, lo cual indica que apenas si les alcanzaba para vivir.
\end{abstract}

Palabras clave: trabajadoras, gasto doméstico, canasta básica, Ciudad de México

Recibido: 17 de febrero de 2021 . Aprobado: 31 de marzo de 2021. 


\section{Introducción}

Ángela Valihache, costurera de la Ciudad de México, tenía su taller doméstico de costura en la $3^{\text {a }}$ calle de Lerdo, número 69 , al centro de la capital mexicana. Se había empleado antes de cumplir 25 años en la tienda comercial de ropa llamada El Traje Obrero, ubicada en la $7^{\mathrm{a}}$ calle de Capuchinas, donde elaboraba pantalones. Posteriormente, prestó sus servicios como costurera para La Malvarosa, en la $1^{\text {a }}$ de Victoria, número 25, para confeccionar el mismo tipo de prendas con telas de otomán y casimir. Esta trabajadora percibía $\$ 7.50$ pesos por semana y con esta cantidad mantenía a sus dos hermanas. Sus gastos cotidianos consistían en alimentos, vestimenta, combustibles y alojamiento. Y cuando se enfermaban del estómago, como normalmente ocurría, asistían al homeópata. ${ }^{1}$

Por otra parte, la tortillera Antonia Delgadillo, quien vivía en una vecindad ubicada en Canal del Norte, número 5, lote F, se ganaba la vida elaborando tortillas, un alimento conformado a base de maíz que era parte esencial de la dieta de los trabajadores y los sectores populares. En las encuestas que aplicaban los inspectores del Departamento del Trabajo, esta mujer informaba que trabajaba entre 6 y 9 horas diariamente. Esto le aseguraba un ingreso de $\$ 5.00$ pesos a la semana para mantener a su grupo familiar compuesto por tres personas. ${ }^{2}$ Cabe mencionar que los gastos en necesidades básicas de la familia de esta trabajadora eran similares a los de la costurera Valihache, aunque no informaba a los inspectores si de sus ingresos totales destinaba gastos a la asistencia médica.

Por otro lado, cabe mencionar que los elementos característicos de estas trabajadoras tenían rasgos en común a pesar de que pertenecían a trabajos distintos. En primer lugar, se trataba de mujeres que eran subcontratadas para desarrollar actividades productivas fuera de grandes establecimientos, almacenes o fábricas, con lógicas de trabajo peculiares y sin derechos laborales. En segundo lugar, con las ganancias de su trabajo podían mantener a sus familias y dar sustento a sus hogares. No obstante, también recurrían a estrategias de supervivencia mediante apoyos materiales solidarios. Algunas costureras que confeccionaban ropa en sus talleres domésticos informaban a los inspectores del Departamento del Trabajo que en ocasiones sus vecinas

1 Los datos provienen de la "Encuesta hecha para saber el costo de vida del obrero”, México, 1921, en Archivo General de la Nación [en adelante, AGN], Departamento del Trabajo, caja 294, exp. 15, fs. 14-14v.

2 Véase AGN, México, Departamento del Trabajo, caja 481, expediente 2, foja 5. 
les regalaban la comida, zapatos o vestidos porque no les alcanzaba para cubrir sus necesidades básicas. En otros casos no les cobraban el alquiler porque ellas eran las porteras que vigilaban la vecindad. ${ }^{3}$ Con todo, es posible observar que habitualmente había otros mecanismos de subsistencia al margen de las ganancias derivadas de su trabajo cotidiano. ${ }^{4}$

Otro de los rasgos en común de estas trabajadoras tiene que ver con el espacio productivo y sus condiciones laborales, que se caracterizaban por desarrollarse fuera de lugares regulados por los gobiernos en turno. Por ejemplo, la costurera se dedicaba a su oficio en su taller doméstico, el cual, normalmente, se ubicaba al interior de un cuarto de vecindad carente de servicios. Esta trabajadora, al igual que otras mujeres con su misma condición y a diferencia de las costureras que utilizaban máquinas de coser en talleres industrializados, manufacturaba la ropa de forma manual empleando hilos y agujas. ${ }^{5}$

Por otra parte, la tortillera que prestaba sus servicios para elaborar alimentos que formaban parte de las dietas de las clases populares también desarrollaba su vida productiva domésticamente en pequeños espacios hacinados y sin ventilación. ${ }^{6}$ El lugar de trabajo de la tortillera Antonia Delgadillo ejemplificaba las condiciones de vida y trabajo en las que se insertaban estas productoras. Por ejemplo, en 1917, en San Antonio Tomatlán, cerca de la Penitenciaría, al oriente de la Ciudad de México, había una vecindad con más de 50 accesorias adaptadas para establecer tortillerías.

Los trabajadores se alumbraban con una lámpara de petróleo y una vela de sebo que se colocaba detrás de la puerta para atraer clientes. En sus viviendas

3 "Encuesta hecha para saber el costo de vida del obrero", México, 1921, en AGN, Departamento del Trabajo, caja 294, exp. 15.

4. Para un análisis de las estrategias de supervivencia, Larissa Lomnitz explica que, para poder entender los mecanismos de supervivencia de los grupos sociales marginados, deben analizarse las modalidades económicas de subsistencia, así como las redes de supervivencia que se dan en el marco de la economía informal, paralela a la del mercado, que se caracteriza por el aprovechamiento de los recursos sociales y que opera con base en el intercambio recíproco entre iguales. Véase Larissa Lomnitz, Cómo sobreviven los marginados (México: Siglo XXI, 1975), 11-13.

5 Véase Fernando Vialli Ávila Campos, "Las trabajadoras del hilo y la aguja. Vida, taller y oficio de las costureras en la ciudad de México durante el primer tercio del siglo XX” (Tesis de Maestría en Historia Moderna y Contemporánea, Instituto Mora, 2020).

6 María Teresa Fernández Aceves, “'Antes éramos molineras’: mujeres y trabajo en la industria de la tortilla en Guadalajara, 1920-1940”, Visiones múltiples. El occidente de México desde la antropología y la historia. Tomo I, coords. Guillermo de la Peña y Jorge Aceves (Jalisco: CIESAS Occidente, 2012), 113-115. 
era común ver el humo de los comales que durante el día se esparcía por todas partes y al día siguiente los habitantes salían a la vía pública para "efectuar sus más perentorias necesidades", debido a que pasaban noches asfixiantes en solemnidad. ${ }^{7}$

Ahora bien, tomando como punto de partida el caso de estas trabajadoras y haciendo énfasis en sus rasgos peculiares de modo de trabajo, se corre el riesgo de caer en generalizaciones sobre la pobreza. Es habitual mencionar que durante el contexto posrevolucionario las condiciones de vida de las trabajadoras y de las clases populares eran adversas y que, en su mayoría, la pobreza acompañaba su cotidianidad. ${ }^{8}$ Sin embargo, para evitar estas afirmaciones generales sobre esta clase social es necesario hacer un estudio del gasto doméstico de productos de primera necesidad de las canastas básicas de una costurera y una tortillera -como muestra de esa mano de obra femenina que laboraba- para conocer el impacto económico que tuvieron en sus hogares después de la revolución mexicana. Además, con este cálculo contable, elaborado a partir de las encuestas para saber el costo de la vida obrera aplicadas por el Departamento del Trabajo en 1921, se pueden conocer las dietas de las trabajadoras y la cantidad de calorías consumidas a diario.

De acuerdo con Aurora Gómez-Galvarriato, no solo era necesario conocer el salario de los trabajadores y sus aumentos de acuerdo con los promedios nacionales durante la época referida, sino saber "qué podía comprarse con ellos y cuál habría sido el consumo de calorías y proteínas de una familia que

7 "La vivienda del pobre", El Universal (México), 15 de agosto de 1917: 10.

8 Cabe mencionar que la denominada Ley de Engel, en términos teóricos y prácticos, puede ser de gran utilidad para estipular un medidor de pobreza. Esta ley estipulaba que "mientras mayor fuera el porcentaje destinado al gasto a comprar alimentos, más pobre era una familia”. Véase en Lilia Esthela Bayardo Rodríguez, Entre el lujo, el deseo y la necesidad. Historia del gasto familiar y del consumo moderno en la Ciudad de México, 1909- 1970 (México: El Colegio de México/El Colegio de Jalisco, 2018), 34. Por otro lado, la historiografía con la que se cuenta hasta el momento ha puesto su interés en otros aspectos, que explican la inserción del sector femenino en los espacios laborales diversos, tanto en fábricas como en talleres. Al respecto véanse María Teresa Fernández Aceves, "Los talleres domiciliarios y el trabajo femenino: el caso de Guadalajara, 1930-1950”, Cultura política de los trabajadores (siglos XIX y XX) Prácticas y representaciones. Trabajo y lucha de clases, coord. Miguel Orduña Carson y Alejandro de la Torre (México: UNAM, 2008); Carmen Ramos Escandón, Industrialización, género y trabajo femenino en el sector textil mexicano: el obraje, la fábrica y la compañia industrial (México: CIESAS, 2004); Susie Porter, Mujeres y trabajo en la ciudad de México: condiciones materiales y discursos públicos (18791931), Trad. María Palomar Vera (Zamora: El Colegio de Michoacán, 2008). 
dichos salarios habrían permitido". ${ }^{9}$ En ese sentido, el gasto doméstico cobra relevancia porque nos permite acercarnos a la vida de las trabajadoras a partir de la relación básica gasto-ingreso en el marco de una actividad productiva u oficio. Por tanto, defino el gasto doméstico como la relación existente entre los salarios y los precios de las mercancías compradas para el consumo del hogar. ${ }^{10}$

Ahora bien, es preciso aclarar que el gasto doméstico era muy distinto a los promedios de consumo per cápita porque se construye desde la experiencia real de las personas. A través de esta micro herramienta contable es posible establecer múltiples contextos en la cotidianidad de los trabajadores; de tal forma, el acontecer diario de los grupos o sujetos pertenecientes a las clases populares casi nunca cuadra con las generalizaciones de los estudios macroeconómicos. En ese sentido, cabe mencionar que la selección de casos de las trabajadoras analizadas en este artículo responde a la necesidad de reducir las escalas de análisis de mujeres con oficios distintos y con bajos ingresos para ofrecer una mirada distinta a la propuesta por grandes estructuras que, desde la abstracción, invisibiliza las agencias de estas trabajadoras.

\section{Las encuestas laborales y su aplicación para los estudios sobre el costo de vida}

Para la realización de este artículo consulté las encuestas de gastos familiares elaboradas en 1921 por inspectores del Departamento del Trabajo, perteneciente a la Secretaría de Industria Comercio y Trabajo. De acuerdo con el inspector Eliseo Garza, quien fue comisionado para realizar los cuestionarios en los centros productivos, el objetivo era establecer presupuestos a partir de necesidades básicas y establecer canastas alimenticias para los obreros de la República mexicana. ${ }^{11}$

9 Aurora Gómez-Galvarriato, Industria y revolución. Cambio económico y social en el valle de Orizaba (México: El Colegio de México/Universidad Veracruzana/ Fondo de Cultura Económica, 2016), 281.

10 Comprendo el gasto doméstico como una herramienta contable implementada desde una perspectiva microhistórica a partir de la noción de "tiempo corto" propuesta por Giovanni Levi, para conocer los cambios económicos en la vida de la gente. Véase Giovanni Levi, "Escala de análisis: el ejemplo del consumo", Segundas Jornadas Braudelianas. Historia y Ciencias Sociales (México: Instituto Mora/ Universidad Autónoma Metropolitana, 1995).

11 Eliseo Garza, Estudio sobre el costo de la vida obrera en México (México: Secretaría de Industria, Comercio y Trabajo, 1922). 
Asimismo, es preciso mencionar que las encuestas consultadas para estimar el gasto doméstico de la costurera y tortillera corresponden solo a aquellas que fueron elaboradas para conocer el sistema de trabajo a domicilio en la Ciudad de México. Si bien no se sabe con certeza cuáles fueron las razones por las que esta dependencia intervino en los lugares productivos de los trabajadores de la capital, se infiere que para ese estudio del costo de vida se siguieron modelos europeos basados en los estudios de las canastas básicas de los trabajadores y el consumo de calorías de acuerdo con su actividad física, pues se tenía la idea de que la capacidad de producción estaba en función del mantenimiento de cuerpos sanos e industriosos. ${ }^{12}$

Tampoco se sabe la frecuencia con la que se realizaban las encuestas, aunque se tiene conocimiento de que las autoridades del Departamento del Trabajo tenían el deseo de controlar y reformar las condiciones de trabajo bajo las cuales la mano de obra se insertaba en un contexto social, político y económico convulso a causa de la fase armada. Esto con el ánimo de reducir las demandas, protestas y amenazas de huelga de los trabajadores de la capital.

Asimismo, se infiere que la aplicación de encuestas se llevaba a cabo anualmente por dos razones: la primera es la cantidad de cuestionarios con los que se cuentan entre 1921 y 1922 (alrededor de 120), lo cual indica que no eran tareas paulatinas; la segunda es que, de acuerdo con los reportes del inspector Eliseo Garza, el estudio sobre las condiciones de trabajo de la fuerza laboral de la república llevaban tiempo en registrar los datos de los trabajadores, sistematizar la información y publicarla. Cabe mencionar que en ocasiones se contaba con la opinión de un experto en química de alimentos para establecer las calorías que debían consumirse y esto podía retrasar los resultados finales.

12 De acuerdo con Joel Domínguez, entre finales del siglo XIX y principios del $\mathrm{XX}$, los higienistas orientaban a la población "a consumir alimentos de una manera racional, como estaba sucediendo en Alemania en ese mismo periodo”. Lo mismo ocurría con las clases populares, que además eran segregadas socialmente por sus patrones de consumo de alimentos habituales en las dietas indígenas. Lo mismo ocurría con los soldados, quienes, de acuerdo con sus actividades físicas, "debían consumir la ración de trabajo". Incluso, se recomendaba el consumo de calorías de acuerdo con el tipo de trabajo: caballería, artillería o infantería. Así, "para lograr cubrir estas demandas calóricas, se proponían seguir el modelo alemán, con la creación e instalación de 'cocinas portátiles' en vez del tradicional reparto de provisiones”. Véase Joel Vargas Domínguez. “El alcohol alimento': historias de las metáforas del motor humano y las calorías entre el siglo XIX y el XX” Interdisciplina, 7:19 (2019): 150. 
Lilia Bayardo, por su parte, explica que estas encuestas tenían una justificación que partía del interés de las autoridades por saber el impacto de la revolución en la vida de las personas. De tal forma que la mayor información obtenida de los trabajadores era de gran utilidad para dichos fines. A su juicio, "el principal problema en México seguía siendo la guerra civil que, evidentemente, estaba afectando la producción, los transportes y, en consecuencia, el abastecimiento de los principales productos, provocando su encarecimiento. Tal vez por ello, con el fin de conocer el impacto de la guerra y las crisis en el nivel de vida $[\ldots]$ se aplicaron encuestas sobre el 'costo de vida"'. ${ }^{13}$

Para cumplir con los objetivos de este trabajo analizaré, en primer lugar, el contexto social y económico en el que se encontraba el país del periodo revolucionario. Posteriormente, consideraré de manera general el nivel de los salarios mínimos y el comportamiento de los precios de alimentos de 1921, así como el papel de los inspectores del Departamento del Trabajo que aplicaron estas encuestas de gastos a las trabajadoras. Por último, estudiaré los casos de costo doméstico de la costurera y tortillera con el propósito de evaluar sus condiciones de vida a partir de varios factores: la composición de sus canastas básicas, los gastos destinados a la vestimenta, el pago de vivienda, combustibles y aseo.

\section{Las condiciones sociales después de la fase armada}

Entre 1917 y 1919, México vivió una serie de procesos difíciles que repercutieron en la vida de la población. A 1917 se le conoció como el "año del hambre" y en los periodos posteriores, tanto en México como en Europa, la gripe española atacó a una sociedad ya de por sí debilitada a causa de la guerra y la carestía de alimentos. Otros factores como el índice poblacional fueron afectados a causa de la guerra civil. Entre 1910 y 1920, se registró una caída de la cantidad de habitantes en México. No obstante, a pesar de que la historiografía menciona que el declive de la población se debió a las muertes por la lucha armada, se pueden agregar otros elementos como el menor número de nacimientos a causa de la separación de parejas, la migración a Estados Unidos y las defunciones por la gripe española. ${ }^{14}$

En 1910, el número de población total era de 15.160.369, a diferencia de los 14.334.780 registrados en 1921. Para el caso de la Ciudad de México, el censo

13 Bayardo, Entre el lujo, 59.

14 Bayardo, Entre el lujo, 49. 
de 1921 arrojó una cantidad de habitantes de 906.063, y en ese sentido Lilia Bayardo explica que el descenso pudo deberse "a un incremento en la mortandad por otros factores de 'índole económica', como la desorganización en la cadena productiva, el desabasto y, en consecuencia, las afectaciones a la dieta y con ello a la salud." ${ }^{5}$ Otro de los indicadores que ayudan a explicar este comportamiento económico de 1921 es que, entre 1916 y 1917, el producto interno bruto (PIB) había registrado sus niveles más bajos. El sistema bancario, por su parte, logró reestablecerse hasta la década de los veinte. Al mismo tiempo, se registraba una hiperinflación que favorecía a otros sectores de la población, pero dejaba en la ruina a "muchas familias de la antigua élite”. ${ }^{16}$

Alan Knight, entre otros autores, considera que "es importante evaluar el grado de comercialización”, independientemente de las etiquetas teóricoconceptuales que se utilicen para describir las economías de América Latina. Es decir, el autor proponía observar el grado de participación en el mercado nacional monetizado "en distintos periodos y lugares". ${ }^{17}$ Tomando estas consideraciones al pie de la letra, la economía de México durante el periodo posrevolucionario condensó las reformas y demandas socioeconómicas de larga duración que no solo fueron obra de los "grandes caudillos de la historia de bronce, sino de actores más anónimos: obreros y campesinos”. ${ }^{18}$

En ese sentido, este periodo estuvo caracterizado por las alianzas obreras entre el gobierno sonorense y la Confederación Regional Obrera de México (CROM). Aparentemente tenían el objetivo de propugnar por una mejora en la calidad de vida de los trabajadores a partir del sindicalismo naciente, al menos así se observaba en términos discursivos. En lo práctico la CROM y el Partido Laborista Mexicano (PLM) formaron un proyecto colaboracionista con el Estado para obtener cargos políticos en el gobierno.

Empero, Alan Knight menciona que esta organización de los trabajadores urbanos en el periodo posrevolucionario, a pesar de que aprovecharon una "apertura sociopolítica”, reclamó demandas "economicistas"; es decir, derechos en cuanto a horas y pagos laborales. ${ }^{19}$ No obstante, Knight

15 Bayardo, Entre el lujo, 48-49; Ariel Rodríguez Kuri, Historia del desasosiego. La revolución en la ciudad de México, 1911-1922 (México: El Colegio de México/ Centro de Estudios Históricos, 2010), 22-28.

16 Bayardo, Entre el lujo, 60.

17 Alan Knight, "La revolución mexicana: su dimensión económica, 1900-1930", Historia general de México: de la colonia a nuestros días, coord. Sandra Kuntz (México: El Colegio de México/ Secretaría de Economía, 2010), 475.

18 Knight, "La revolución mexicana”, 486.

19 Knight, "La revolución mexicana", 494. 
menciona que las reformas socioeconómicas emanadas del Congreso Constituyente de 1917, en los artículos 27 y 123, se cumplieron de forma "incremental durante los años veinte y treinta". Esto se debió en buena medida a una relación "dialéctica entre la presión popular, la resistencia de los sectores afectados y la actuación flamante del gobierno posrevolucionario". ${ }^{20}$

Ante estos indicadores demográficos y laborales, el gobierno posrevolucionario tomó algunas medidas para conocer el impacto de la guerra civil en la población mexicana. Uno de ellos fue, desde luego, habilitar al Departamento del Trabajo que venía actuando desde el mandato de Francisco I. Madero como una instancia de gobierno que tenía la facultad de intervenir en el mundo laboral y ser la intermediaria en los conflictos contenciosos. ${ }^{21}$ De acuerdo con Carmen Ramos, el Departamento además de fomentar el trabajo en el país "tendría también injerencia en los conflictos entre los dueños de las fábricas y operarios, consecuencia, según el propio departamento, de las inevitables contradicciones entre capital y trabajo". 22

Por esta razón, en 1921 el Departamento del Trabajo, a través de uno de sus inspectores de nombre Eliseo Garza, se dedicó a levantar encuestas en los lugares de trabajo y se encargó de aplicar cuestionarios a los obreros para conocer sus condiciones laborales y medir el impacto de la revolución en la vida de las personas. Además, como lo veremos más adelante, Eliseo Garza estimó la composición de una canasta básica de alimentos que debía consumirse entre los trabajadores de la república y sus familias, así como los gastos destinados a la vestimenta, aseo y asistencia de baños públicos. Estos costos que la mano de obra desembolsaba diariamente, según los promedios de Eliseo Garza, estaban correctamente relacionados con los índices de precios y salarios de la época.

\section{El panorama general de los salarios mínimos y precios de 1921}

En décadas recientes los estudios sobre la economía en México en el periodo posrevolucionario se basaron en gran medida en las estadísticas macroeconómicas. El objetivo de estos promedios e interpretaciones

20 Knight, "La revolución mexicana”, 489-490.

21 Gómez-Galvarriato, Industria y revolución.

22 Ramos, Industrialización, género y trabajo, 306. También véase Jeffrey Bortz y Marcos Águila, "Earning a Living. A History of Real Wages in Twentieth Century Mexico", Latin American Research Review, 41 (2006). 
económicas del país era medir el crecimiento nacional sobre este rubro y el impacto que tuvo en ciertos sectores de la sociedad. Algunas propuestas historiográficas, como la de Enrique Cárdenas, destacan que durante los años veinte el desarrollo financiero fue "lento, con altibajos y desigual sectorialmente."23

En la industria textil, "los salarios estuvieron recientemente correlacionados con los movimientos de huelga, y menos con la productividad en los primeros años del decenio de 1920". ${ }^{24}$ Luis Aboites y Engracia Loyo mencionan que durante el periodo posrevolucionario "las condiciones de vida de los trabajadores y en general del grueso de la población no habían mejorado”. Por el contrario, prevalecían "las jornadas extenuantes y los bajos salarios, además del hacinamiento, la falta de higiene y de servicios médicos.”25

Tanto el sector femenino como la infancia seguían sufriendo la falta de contratos laborales. De acuerdo con Aboites y Loyo, los niños menores de 16 años formaban parte del $80 \%$ del sector productivo y tanto "prevalecían los bajos salarios [...] que la propia Secretaría de Trabajo, Industria y Comercio los consideraba insuficientes para adquirir la canasta básica”. ${ }^{26}$ Con respecto a la adquisición de productos de primera necesidad, Aurora GómezGalvarriato y Aldo Musacchio identificaron un "contraste entre la estabilidad de precios durante el porfiriato y su mucho mayor fluctuación durante el periodo $1917-1929 ” .{ }^{27}$

Estos autores reconocieron varios factores que explicaron la oscilación de costos durante la época. En 1918, las restricciones a las exportaciones de Estados Unidos a México se habían eliminado, lo cual implicó que la producción nacional aumentara. "A partir de ese año el cambio en los precios internos estuvo muy influido por los ciclos económicos internacionales.”28 Un año después, en todos los países industrializados, "la deflación cedió paso a la expansión económica y a la inflación”. En 1920, los ajustes económicos propiciaron de nueva cuenta una caída en la producción y los precios. México por su parte, durante la expansión económica internacional, “perdió grandes

23 Enrique Cárdenas, El largo curso de la economía mexicana (México: El Colegio de México/ Fondo de Cultura Económica, 2015), 357.

24 Cárdenas, El largo curso, 368.

25 Luis Aboites y Engracia Loyo, "La construcción del nuevo Estado, 1920-1945”, Historia general de México (México: El Colegio de México, 2011), 615.

26 Aboites y Loyo, "La construcción del nuevo Estado", 616.

27 Aurora Gómez-Galvarriato y Aldo Musacchio, "Un nuevo índice de precios para México, 1886-1929”, El Trimestre Económico, 67: 265 (2000): 55.

28 Gómez-Galvarriato y Musacchio, "Un nuevo índice”, 63; Jeffrey Bortz y Marcos Águila, "Earning a Living”, 2016. 
cantidades de plata debido a que su alto precio en el exterior generó incentivos para que se exportara”. Esto propició que los costos aumentaran de manera paralela a los ajustes del plano internacional. ${ }^{29}$

Aurora Gómez-Galvarriato ofrece un estudio general de salarios entre 1900 y 1929 y menciona que durante la última década del porfiriato los salarios reales se mantuvieron relativamente estables. Entre los años 1907 y 1911 hubo variaciones y decrecieron a consecuencia de la inflación que se vivió en ese periodo. La caída de los sueldos reales "durante este periodo pudo haber aumentado el descontento de los obreros con el régimen de Porfirio Díaz". Para esta autora, al ver esta caída en los salarios "desde una perspectiva amplia, resulta demasiado pequeña como para que haya sido una causa importante de la Revolución mexicana”. ${ }^{30}$

A pesar de que centra su estudio en Orizaba, Gómez-Galvarriato explica que la tendencia de los salarios reales del porfiriato puede generalizarse para los obreros industriales de la región central de México durante este periodo, "puesto que su evolución no fue resultado de cambios en los salarios nominales" de la industria textil de Orizaba. ${ }^{31}$ En el caso del Distrito Federal, entre 1925 y 1929, los salarios y el empleo en la industria algodonera tuvieron variaciones con respecto al caso de Veracruz. En aquella entidad federativa el salario nominal diario se estipulaba en 2,34 pesos en 1925; cuatro años después se fijó en 2,76 con un promedio de 9,6 horas trabajadas. ${ }^{32}$

\section{Los inspectores y las encuestas de gastos familiares}

En la Ciudad de México las encuestas realizadas durante los años 1909 a 1970 mostraron los datos de gastos familiares de los diversos tipos de sectores sociales de la capital, entre ellos los populares. ${ }^{33} \mathrm{~A}$ juicio de Lilia Bayardo, las

29 Gómez-Galvarriato y Musacchio, “Un nuevo índice”, 63.

30 Gómez-Galvarriato, Industria y revolución, 277.

31 Gómez-Galvarriato, Industria y revolución, 279.

32 Cfr. Con los datos ofrecidos para Veracruz en que el salario nominal diario en 1925 era de 3.04 a diferencia del año de 1929 que estaba estipulado en 3.91, con una cifra de -22. 4 horas trabajadas. Véase Gómez-Galvarriato, Industria y revolución, 278.

33 Lilia Bayardo estudió las encuestas de gastos familiares entre 1909 y 1970 y recuperó la noción de 'clases populares' propuesta por José Iturriaga, quien, con base en el censo de 1895, "incluyó en dicha categorización a trabajadores urbanos, concretamente obreros y jornaleros, industriales, artesanos, pequeños comerciantes y vendedores ambulantes”. Véase Bayardo, Entre el lujo, 33; Clara E. Lida, “Qué son las clases populares?”. Los modelos europeos frente al caso español en el siglo XIX”, Historia Social, 27 (1997): 4. 
primeras encuestas, concernientes a los años de 1909, 1914 y 1921, fueron realizadas "entre los sectores peor pagados del sector productivo". ${ }^{34}$ Como ya indiqué, en esta investigación solo utilizaré la encuesta elaborada por el Departamento del Trabajo en 1921. La aplicación de encuestas de gastos familiares llevadas a cabo por el Departamento del Trabajo correspondientes a los años 1921 y 1926 fue resultado del interés del gobierno de medir el impacto de la guerra civil y "la crisis en el nivel de vida de los grupos trabajadores". ${ }^{55}$ No obstante, no fueron las únicas con las que se contó para medir el costo de la vida obrera. Por lo menos desde el porfiriato se intentaba medir el consumo de bienes de primera necesidad entre los sectores menos favorecidos de la sociedad mexicana.

A partir del incremento de los niveles de consumo con el proceso de industrialización se incentivó la venta de productos diversos, desde cigarros hasta bebidas embriagantes como el pulque que tenía un arraigo popular debido a que podía adquirirse a bajos costos. Estas encuestas sin duda registraban la adquisición de varios alimentos y vestimenta. Al respecto, los trabajadores no gastaban en prendas lujosas, los sectores populares solo podían contar con telas sencillas con las que podían confeccionar ropa en sus hogares. ${ }^{36}$ Entre 1914 y 1921, los elaboradores de las encuestas de gastos familiares registraban aquellos destinados a alimentación, alquileres, aseo y transportes. Conforme crecían las necesidades de los trabajadores de informarse y trasladarse a varios puntos de la Ciudad de México, en 1921 se percibió "un pequeño porcentaje del gasto destinado a periódicos y pasajes de tranvía $[\ldots]$ en el caso del transporte, con el crecimiento y transformación de la ciudad, se hizo necesario este nuevo gasto", el cual costaba tres centavos. $^{37}$

Por otro lado, entre 1921 y 1922, Eliseo Garza publicó un estudio sobre el costo de la vida obrera en la República mexicana. La característica de este documento es que en su composición se sintetizaron los resultados obtenidos de las encuestas aplicadas en los lugares de trabajo. Otro de los objetivos, además de medir el impacto de la fase armada en la población, fue "calcular el costo de la vida de los obreros en las diferentes regiones y centros industriales de la república [...] tomando en consideración las observaciones que a este respecto [presentaban] los higienistas, químicos y fisiólogos". ${ }^{88}$ Es

\footnotetext{
34. Bayardo, Entre el lujo, 33.

35 Bayardo, Entre el lujo, 59.

36 Bayardo, Entre el lujo, 110-115.

37 Bayardo, Entre el lujo, 113.

38 Eliseo Garza, Estudio sobre el costo, 1.
} 
decir, se apoyó en consideraciones científicas que al respecto pudieran contribuir en la comprensión del costo de la vida de los sectores productivos.

Eliseo Garza justificaba la necesidad de contar con una mirada experta en estudios químicos sobre el consumo de alimentos y calorías necesarias para las familias obreras. Al respecto, contó con las recomendaciones que hizo el químico Miguel Cordero, quien era encargado de la sección de alimentos del Laboratorio Técnico y miembro de la Sociedad Química Americana. Las observaciones de Cordero giraban en torno a la composición química de los alimentos, los nutrientes, las calorías y la dieta de los obreros. ${ }^{39}$ Cabe mencionar que el análisis químico nutrimental era una práctica habitual entre médicos y otros especialistas científicos que vertían sus opiniones con respecto al consumo de calorías en las dietas de la población entre finales del siglo XIX y principios del XX. De modo que “al poder cuantificar los elementos constitutivos de los alimentos, los higienistas o salubristas podían elaborar prescripciones acerca de las relaciones necesarias para garantizar la salud". ${ }^{40}$

Habitualmente, estos especialistas empleaban metáforas relacionadas con la combustión de un motor humano y el trabajo que este debía efectuar. Para su funcionamiento se establecía que "las materias orgánicas, conocidas como alimentos ternarios, eran las encargadas de producir 'movimiento calorífico'. Estos se combinaban con el oxígeno durante la respiración, y así se podía medir la cantidad de diversos alimentos que equilibraban este consumo”. Bajo este principio se recomendaba equilibrar el carbono en la dieta de la población, sobre todo de las clases populares porque en estas recaía la fuerza de trabajo. Por tanto, se establecían estándares de cantidades de calorías por tipo de trabajo realizado. Entre estas se destacaban las adquiridas por alimentos ricos en carbohidratos, entre otros. Así, "las calorías se instauraron como medios para que los mismos ciudadanos conocieran y modificaran sus patrones de consumo". ${ }^{41}$

Por su parte, el especialista en alimentos Miguel Cordero consideraba que los productos necesarios para el consumo de los obreros eran las grasas que

39 Se utiliza la categoría "obreros", en lugar de "trabajadores", porque las encuestas elaboradas por el Departamento del Trabajo utilizan ese término. De acuerdo con Lilia Bayardo, las encuestas sobre el costo de vida de los sectores sociales productivos referían una conceptualización que fue cambiando paulatinamente. Por ejemplo, la de 1909 implementó la noción de "clases populares", la de 1914 "familias obreras" y la de 1921 "habló de obreros". Véase Bayardo, Entre el lujo, 32 y 33.

40 Vargas, “El alcohol alimento”, 148.

41 Vargas, “"El alcohol alimento”, 149-150. 
provenían de los animales. Entre ellos destacó la carne, el huevo y la leche. Además, agregó las que proporcionaban los vegetales como el aceite de oliva, el ajonjolí, las nueces y el coco. Estos productos, al ser absorbidos en el organismo por medio del metabolismo, "generaban 9,3 calorías por gramo". Estos alimentos constituían reservas calóricas y preveían de "emergencias futuras en caso de pobreza o enfermedad”. ${ }^{42}$ El químico Cordero estableció que otro criterio de selección de los alimentos que debían consumirse era simplemente su composición química. Determinó que la ingesta alimenticia y de calorías debía estar estipulada con relación al trabajo que realizaban. Posteriormente, asignó para las familias obreras las raciones y las calorías indispensables para su sostenimiento (Tabla 1).

Tabla 1. Lista de alimentos, raciones y calorías para trabajadores de la República mexicana, 1921-1922

\begin{tabular}{|l|r|r|}
\hline \multicolumn{3}{|c|}{ Alimentación } \\
\hline Alimento & Gramos & \multicolumn{1}{|c|}{ Calorías } \\
\hline Maíz & 1.000 & 3.557 \\
\hline Pan & 200 & 445 \\
\hline Frijol & 200 & 516 \\
\hline Arroz & 100 & 347 \\
\hline Carne & 500 & 2.050 \\
\hline Leche & 500 & 2.050 \\
\hline Azúcar & 200 & 820 \\
\hline Café & 50 & 115 \\
\hline Manteca & 100 & 930 \\
\hline Chile & 50 & 18 \\
\hline Legumbres & 300 & 349 \\
\hline Sal & 50 & - \\
\hline & Total & 11.200 \\
\hline
\end{tabular}

Fuente: Eliseo Garza, Estudio sobre el costo de la vida obrera en México (México: Secretaría de Industria, Comercio y Trabajo, 1922), 7.

Como se puede observar en la tabla, se determinaron las calorías que los trabajadores debían consumir de acuerdo con el tipo de labor que desempeñaban: ya fuera trabajo sedentario, muscular ligero o extremo. A pesar de que no se estableció una diferencia entre una y otra categoría, se puede inferir que el elemento que las distinguía era la cantidad de energía gastada en cada labor.

42 Garza, Estudio sobre el costo, 3. 
Por otro lado, la dieta propuesta por los inspectores estaba compuesta por alimentos que comúnmente se consumían entre los sectores populares de la sociedad mexicana. Entre estos destacaban el maíz, el chile, el frijol, la manteca, el café y la carne (véase la tabla 2). Cabe aclarar que esta composición alimenticia fue conservada por los peones o albañiles en el siglo XIX, y era similar a la que "había estado presente durante dos mil años, al menos en Mesoamérica, constituida por maíz, frijoles, chile, pulque”.43 Además, debía agregarse la carne que, al menos desde el siglo XVIII, “ocupaba un lugar destacado en el consumo urbano". ${ }^{44}$

\section{Tabla 2. Índices de precios de alimentos de primera necesidad, Ciudad de México, 1921}

\begin{tabular}{|l|c|c|}
\hline \multicolumn{1}{|c|}{ Alimento } & Cantidad & Precio (centavos) \\
\hline Frijol negro & $1 \mathrm{~kg}$ & 24 \\
\hline Arroz & $1 \mathrm{~kg}$ & 40 \\
\hline Sopa & $1 \mathrm{~kg}$ & 40 \\
\hline Pan & $1 \mathrm{~kg}$ & 50 \\
\hline Carne de res de tercera & $1 \mathrm{~kg}$ & 64 \\
\hline Azúcar mascabado corriente & $1 \mathrm{~kg}$ & 30 \\
\hline Café planchuela & $1 \mathrm{~kg}$ & 45 \\
\hline Leche & $1 \mathrm{~L}$ & 30 \\
\hline Pulque & $1 \mathrm{~L}$ & 12 \\
\hline Manteca & $1 \mathrm{~kg}$ & 110 \\
\hline Masa (1918) & $1 \mathrm{~kg}$ & 8,5 \\
\hline Petróleo & $1 \mathrm{~L}$ & 24 \\
\hline Carbón & $1 \mathrm{~kg}$ & 9 \\
\hline Vela & $1 \mathrm{~kg}$ & 10 \\
\hline Jabón & $1 \mathrm{~kg}$ & 114 \\
\hline
\end{tabular}

Fuente: Elaboración propia a partir de: El Universal (México) 3 y 4 de enero de 192 1: 10 y 11; "Encuesta hecha para saber el costo de vida del obrero", Ciudad de México, 1921. AGN, México, Departamento del Trabajo, caja 294, expediente 15.

Vale la pena mencionar que los autores del estudio que he referido no precisaban si esas cantidades de alimentos eran accesibles a todos los trabajadores y con qué frecuencia podían consumirlos. Se limitaron a establecer los indicadores nutritivos en las dietas familiares a partir del uso de estadísticas, para apegarse "resueltamente a las exigencias de la gran masa

43 Arnold Bauer, Somos lo que compramos. Historia de la cultura material en América Latina (México: Taurus, 2001), 195.

44 Enriqueta Quiroz, Entre el lujo y la subsistencia: Mercado, abastecimiento y precios de la carne en la ciudad de México, 1750-1812 (México: El Colegio de México/ Instituto de Investigaciones Dr. José María Luis Mora, 2005), 48. 
productora". ${ }^{5}$ No obstante, las apreciaciones tanto de Garza como de Cordero estaban alejadas de la cotidianidad en las casas de las trabajadoras. Los promedios sobre el costo de la vida obrera que realizaron estos funcionarios del gobierno expusieron registros de gastos menores a los que realmente se desembolsaban, como lo veremos a continuación con los presupuestos de una costurera de taller doméstico y una tortillera en la Ciudad de México en el año de 1921.

\section{El gasto doméstico en los hogares de las trabajadoras}

En 1921 la costurera Ángela Valihache reportó a los inspectores del Departamento del Trabajo las actividades que llevaba a cabo en un taller de costura, ubicado en la $3^{\text {a }}$ calle de Lerdo, número 69. Esta trabajadora comenzó a coser ropa en 1906 en el contexto social que dio luz a la obra "La Rumba”, de Ángel de Campo, que versa sobre la vida sórdida de la costurera Remedios, quien trabajaba en la casa de modas de una modista de París. Esta mujer tenía que recorrer a diario los arrabales urbanos de la Ciudad de México a inicios del siglo XX en busca de ascenso social para salir de un barrio hacinado, soez y abigarrado del centro de la capital mexicana. ${ }^{46}$

Ángela Valihache, por su parte, había trabajado para las tiendas El Traje Obrero, ubicada en la $7^{\mathrm{a}}$ calle de Capuchinas y para La Malvarosa, de la $1^{\mathrm{a}}$ calle de Victoria, número 25. Se dedicaba a confeccionar pantalones de otomán y casimir por lo que recibía por cada pieza confeccionada, la cantidad de 750 centavos a la semana y 3000 centavos al mes. Con estos ingresos la costurera podía abastecerse de alimentos, combustible, vestido y vivienda. Su canasta básica estaba compuesta de productos como el café, carne de res de tercera, frijol negro, arroz, azúcar mascabado corriente, leche, pan, sopa, legumbres y pulque (véase tabla 3 ).

45 Garza, Estudio sobre el costo, 7.

46 Ángel De Campo, La rumba (México: Conaculta, 2013). 
Tabla 3. Presupuesto mensual de la costurera Ángela Valihache, 750 centavos por semana, 3000 al mes, Ciudad de México, 1921

\begin{tabular}{|c|c|c|c|c|c|c|c|}
\hline $\begin{array}{l}\text { Gasto } \\
\text { mensual }\end{array}$ & & & Producto & & & $\begin{array}{l}\text { Compra } \\
\text { mensual }\end{array}$ & $\begin{array}{c}\text { Costo } \\
\text { mensual }\end{array}$ \\
\hline & $\%$ & Centavos & & $\%$ & Centavos & kilos & Centavos \\
\hline Alimento & 55,64 & 2.617 & Café & 1,42 & 67 & 1,5 & 67 \\
\hline Combustible & 17,86 & 840 & $\begin{array}{l}\text { Carne de res de } \\
\text { tercera }\end{array}$ & 10,2 & 480 & 7,5 & 480 \\
\hline Vestido & 5,23 & 246 & Frijol negro & 3,82 & 180 & 7,5 & 180 \\
\hline Vivienda & 21,26 & 1.000 & Arroz & 2,55 & 120 & 3,0 & 120 \\
\hline \multirow[t]{7}{*}{ Total } & 100 & 4.703 & $\begin{array}{l}\text { Azúcar mascabado } \\
\text { corriente }\end{array}$ & 1,91 & 90 & 3,0 & 90 \\
\hline & & & Leche & 9,56 & 450 & $15 \mathrm{~L}$ & 450 \\
\hline & & & Pan & 12,75 & 600 & 12 & 600 \\
\hline & & & Sopa & 2,55 & 120 & 3 & 120 \\
\hline & & & Legumbres & 3,18 & 150 & Sin dato & Sin dato \\
\hline & & & Pulque & 7,65 & 360 & $30 \mathrm{~L}$ & 360 \\
\hline & & & Total & 55,64 & 2.617 & & \\
\hline
\end{tabular}

Fuente: Elaboración propia a partir de "Encuesta hecha para saber el costo de vida del obrero", Ciudad de México, 192 1; AGN, México, Departamento del Trabajo, caja 294, expediente 15 .

Cabe mencionar que el estudio alimenticio de Eliseo Garza y Miguel Cordero sirvió para obtener las calorías de cada producto que consumía la costurera Ángela Valihache y su grupo familiar, que estaba compuesto por tres mujeres, incluyendo a la trabajadora. Para ello, se dividió por cada miembro de la familia la cantidad mensual de alimentos comprados por kilos. Por ejemplo, de los alimentos que se observan en la tabla 3 en la dieta de la costurera se consumían más cantidades de pan, pulque y el consumo mensual per cápita de los mismos productos era de 4 kilos y 10 litros de pulque, respectivamente.

La variación de productos en la dieta de la costurera Valihache no es sinónimo de una mejor alimentación a pesar de que incluía arroz, sopa y legumbres. Una de las posibles razones por la cual consumía menos cantidades de carne y frijoles se debe los precios estipulados para adquirir estos alimentos (véase la tabla 2). Aunque podía destinar una parte considerable de sus ingresos a la compra de pan, pulque y leche.

En comparación con el estudio de Eliseo Garza, con respecto al consumo de calorías, el caso de la costurera refleja un contraste considerable porque esta trabajadora obtenía 49.930 calorías al mes de los alimentos que comía (véase tabla 4). Es decir, una cantidad mayor a la propuesta por el inspector para un grupo familiar tradicional (padre, madre, hijos). 
Tabla 4. Calorías por alimentos consumidos por persona, Ciudad de México, 1921

\begin{tabular}{|l|r|r|}
\hline \multicolumn{1}{|c|}{ Alimento } & Gramos/ Litros & Calorías \\
\hline Carne de res & 2.500 & 10.250 \\
\hline Frijol negro & 2.500 & 6.450 \\
\hline Arroz & 1.000 & 3.470 \\
\hline Sopa & 1.000 & Sin dato \\
\hline Pan & 4.000 & 8.900 \\
\hline Café & 0,5 & 1,15 \\
\hline Azúcar & 1.000 & 4.100 \\
\hline Leche & 4 & 16.400 \\
\hline Pulque & 10 & Sin dato \\
\hline Legumbres & 300 & 349 \\
\hline & Total & 49.930 \\
\hline
\end{tabular}

Fuente: Elaboración propia a partir de Eliseo Garza, Estudio sobre el costo de la vida obrera en México (México: Secretaría de Industria, Comercio y Trabajo, 1922) y tabla 3.

Como se puede observar en la tabla 4, el único alimento que aparece sin calorías es el pulque; no obstante, esta bebida era habitual en la canasta alimentaria de los sectores populares. La historiografía menciona que, por lo menos desde el porfiriato, "el consumo de pulque alcanzaba su punto más alto" y que el Ayuntamiento de México recibía informes de que "no menos del $70 \%$ de habitantes de la ciudad consumía pulque". ${ }^{47}$

Empero, es preciso señalar que no siempre se bebía dentro de las pulquerías. En algunos casos se compraba para consumir en los hogares de los trabajadores, como sucedía con la costurera. En ese sentido, y de acuerdo con Diego Pulido Esteva, Ángela Valihache formaba parte de "la clientela de las pulquerías [que representaba] una multitud compuesta por obreros, artesanos y trabajadores de la calle agolpados en las puertas". ${ }^{48}$

Las percepciones médicas que desde el porfiriato se hacían con respecto al consumo de pulque estaban enfocadas a considerarlo como una bebida saludable que formaba parte de "los alimentos llamados 'nervinos' o alcohólicos", idóneos para los trabajadores, debido al esfuerzo físico implementado. ${ }^{49}$ Por otra parte, el estudio de Eliseo Garza y del químico

47 Diego Pulido Esteva, “¡A su salud! Sociabilidades, libaciones y prácticas populares en la Ciudad de México a principios del siglo XX” (Tesis de Doctorado en Historia, El Colegio de México, 2012), 38.

48 Pulido, “¡A su salud!...”, 39-40.

49 Rodolfo Ramírez Rodríguez, "La querella por el pulque. Auge y ocaso de una industria mexicana (1890-1930)" (Tesis de Doctorado en Historia, UNAM, 2014), 96. 
Miguel Cordero no consideró esta bebida como un alimento recurrente en la dieta de los trabajadores. Una de las razones que puede explicar la ausencia es que a largo plazo originaba alcoholismo y la degeneración moral de los sectores productivos. No es casual que las autoridades sanitarias y laborales utilizaran constantemente este discurso en la década de los veinte.

Si comparamos los patrones de consumo de la costurera con los de la tortillera, nos podemos dar cuenta de que hay similitudes con respecto a la ingesta de pan y pulque. Aunque entre la adquisición de carne, leche y pulque se consumieran las mismas cantidades, como veremos a continuación. En 1921, la tortillera Antonia Delgadillo de 25 años, quien vivía en Canal del Norte, número 5, lote $\mathrm{F}$, informaba a los inspectores del Departamento del Trabajo que diariamente trabajaba elaborando tortillas entre 6 y 9 horas, por lo cual le pagaban $\$ 5.00$ pesos a la semana. Cabe mencionar que del trabajo de esta mujer dependían un adulto, un niño y gran parte de sus ingresos se destinaban a los alimentos, al pago de vivienda y aseo (Tabla 5).

\section{Tabla 5. Presupuesto mensual de la tortillera Antonia Delgadillo, 500 centavos por semana, 2000 al mes, Ciudad de México, 1921}

\begin{tabular}{|c|c|c|c|c|c|c|c|}
\hline $\begin{array}{c}\text { Gasto } \\
\text { mensual }\end{array}$ & & & Producto & & & $\begin{array}{l}\text { Compra } \\
\text { mensual }\end{array}$ & $\begin{array}{c}\text { Costo } \\
\text { mensual }\end{array}$ \\
\hline & Porcentaje & Centavos & & Porcentaje & Centavos & Kilos & Centavos \\
\hline Alimento & 39,7 & 2.730 & Leche & 3,05 & 210 & 7.5 & 210 \\
\hline Combustible & 8,3 & 570 & Pulque & 3,05 & 210 & 7.5 & 210 \\
\hline Aseo & 16,6 & 1.140 & Carne & 8,72 & 600 & 7.5 & 600 \\
\hline Vestido & 11,9 & 821 & Pan & 6,43 & 450 & 22.5 & 450 \\
\hline Alquiler & 23,3 & 1.600 & Sopa & 1,30 & 90 & 3.6 & 90 \\
\hline \multirow[t]{7}{*}{ Total } & 100,0 & 6.861 & Frijoles & 2,18 & 150 & 3.6 & 150 \\
\hline & & & Tortillas & 8,72 & 600 & 12 & 600 \\
\hline & & & Manteca & 2,18 & 150 & 6.6 & 150 \\
\hline & & & Azúcar & 2,18 & 150 & 4.5 & 150 \\
\hline & & & Café & 0,87 & 60 & 2.7 & 60 \\
\hline & & & Legumbres & 0,87 & 60 & Sin dato & 60 \\
\hline & & & Total & 39,7 & 2.730 & - & - \\
\hline
\end{tabular}

Fuente: Elaboración propia a partir de AGN, México, Departamento del Trabajo, caja 481, expediente 2 , foja 5 .

En la tabla 5 se muestran los productos que habitualmente consumía la tortillera Antonia Delgadillo. Lo que se observa es un patrón de consumo de alimentos como la leche, el pulque y la carne porque se podían comprar las mismas cantidades al mes con 500 centavos que obtenía por elaborar tortillas. Asimismo, llama la atención la cantidad consumida de ese producto que le 
permitía sustentar su hogar. Quizá una de las razones por las cuales los 12 kilos de tortillas eran frecuentes en la mesa de la trabajadora se deba a la naturaleza del oficio que desarrollaba; no obstante, que se dedicara a ello no significaba que esto disminuyera el precio y pudiera enriquecer su canasta básica de maíz.

Ahora bien, es necesario apuntar que Antonia Delgadillo tenía un vínculo en común con la costurera a partir de los alimentos que consumían. Una muestra de ello es la alta ingesta de carbohidratos presentes en alimentos como el pan. Lejos de manifestarse como un indicador de una alimentación balanceada y sana, la presencia de pan en los hogares de las trabajadoras se debía a su bajo costo. En 1921 el pan ya no se consideraba como un bien ajeno a las clases populares y como un factor sensible de una posición alta entre la población como ocurría desde mediados del siglo XIX; ;0 por el contrario, con los ingresos tanto de la costurera como de la tortillera se podían destinar 20 centavos por tres o cuatro piezas de pan. A esto hay que agregar que el precio de los bolillos en el año referido era de 50 centavos por kilo. ${ }^{51}$ Un costo poco elevado si se compara con los precios de 1918, los cuales fluctuaban entre los 9 y 9,25 centavos por pieza. ${ }^{52}$ Aun así, el pan podía ser consumido de manera constante en la dieta de los trabajadores.

Ahora bien, en el consumo de alimentos de la costurera y la tortillera se incluye la carne de res de tercera calidad. Esto implicaba que el buen sabor e higiene de este producto no se garantizaba a los consumidores de la época, lo único que causaba preocupación en la compra de carne era el precio con el cual se expandía. Tanto Antonia Delgadillo como Ángela Valihache llevaban a las mesas de sus casas 7,5 kilos de carne de res al mes. Si se estima la ingesta de esta proteína por día, cada trabajadora tenía la posibilidad de adquirir 250 gramos de carne en tanto que el kilo de este producto estaba estipulado en 64 centavos, lo cual indica que la costurera que ganaba 750 centavos a la semana por coser ropa destinaba 16 centavos diarios en retazos de res. Por su parte la tortillera, de los 500 centavos obtenidos de ingreso a la semana por dicha

50 Enriqueta Quiroz, "Vivir de un salario: el costo del consumo doméstico", "Instantáneas" de la Ciudad de México. Un álbum de 1883-1884, coords. Alicia Salmerón y Fernando Aguayo (México: Instituto Mora/ Universidad Autónoma Metropolitana, Unidad Cuajimalpa, 2013), 126-127.

51 El Universal (México) 4 de enero de 1921: 11.

52 "Promedio del costo de la vida del obrero en las municipalidades del Distrito Federal en el mes de diciembre de 1918", Ciudad de México, 1918, AGN, México, Departamento del Trabajo, caja 116, expediente 2, fojas 145 y 121. 
labor, podía desembolsar alrededor de 10,6 centavos diarios en el consumo de carne de res de tercera. ${ }^{53}$

Los demás alimentos como la sopa, los frijoles, azúcar y manteca, aunque representaban índices menores de consumo, alcanzaban para satisfacer las necesidades básicas de estas trabajadoras y de los integrantes de sus grupos familiares en la medida en que eran jefas de hogar. Ahora bien, es necesario mencionar que estas mujeres podían destinar gran parte de sus ingresos a otros gastos como la vestimenta, el combustible, vivienda, aseo y para ello tenían que trabajar largas jornadas al día. En ese sentido, como se puede ver en las tablas de presupuesto mensual, tanto a la costurera como a la tortillera no les alcanzaba para poder vivir con los sueldos que percibían.

A diario las protagonistas de esta historia se enfrentaban a labores agotadoras: por un lado, la costurera confeccionaba prendas con el uso prolijo de diversas telas para los cajones de ropa que las contrataban a destajo y, por otro, la tortillera representaba a "las mujeres se levantaban al alba para hacer la masa y las tortillas que son la base de la dieta mexicana. Puesto que la masa fermenta en pocas horas, debe prepararse una fresca todos los días; este trabajo exigía de las mujeres más tiempo del que toma hacer pan para toda la semana”. ${ }^{4}$

Otro gasto considerable de los presupuestos de estas trabajadoras era el destinado a vivienda. No obstante, llama la atención que la mayoría de los sectores populares vivía en vecindades hacinadas que tenían problemas de higiene y alumbrado. Esta situación no era particular de la década de los años veinte, aunque entre 1920 y 1922 la ciudad estuvo inmiscuida en un caos higiénico y falta de agua potable. Asimismo, el estado material de las viviendas seguía siendo una dificultad en el escenario urbano desde principios del siglo. De acuerdo con Pablo Piccato, "en los viejos barrios cercanos al centro urbano y en muchas colonias para las clases bajas de reciente creación, la gente vivía en vecindades, viviendas de uno o dos pisos que carecían de la clara autonomía espacial de las casas modernas”. ${ }^{55}$

53 Para conocer el precio de la carne de res véase El Universal (México) 3 de enero de 1921:10. Sobre las estimaciones del consumo por trabajadora vale la pena agregar que son cálculos de elaboración propia a partir de AGN, México, Departamento del Trabajo, caja 481, expediente 2, foja 5 y "Encuesta para saber el costo de vida del obrero", Ciudad de México, 1921. AGN, México, Departamento del Trabajo, caja 294, expediente 15 , fojas 14 y $14 \mathrm{v}$.

54 Dawn Keremitsis, "Del metate al molino: La mujer mexicana de 1910 a 1940", Historia Mexicana, 33: 2 (1983): 285.

55 Pablo Piccato, Ciudad de sospechosos. Crimen en la ciudad de México, 1900-1931 (México: CIESAS, 2010), 55. 
Durante 1921, en algunas calles aledañas a la calle de Cocheras (hoy República de Colombia), algunas mujeres se quejaban ante las oficinas de Obras Públicas que en los hogares se filtraba agua en mal estado de los muros divisorios de las habitaciones y del tubo de desagüe a los caños. Las recámaras, por su parte, estaban cuarteadas, el techo de los comedores con polilla, lo que provocaba la caída constante de tierra del acorazado. Las instalaciones del drenaje eran deficientes porque al no tener cloacas el agua sucia se estancaba en los pisos. ${ }^{56}$

Como se puede apreciar en las tablas 3 y 4, el 21,26 y 23,3\% de los gastos destinados al pago de alquileres representaron otro patrón de consumo que correspondía a una lógica de encarecimiento de viviendas que estuvo muy marcada a inicios de siglo y que pudo haber sido una continuidad hasta la etapa de la reconstrucción. Por ejemplo, "en la colonia La Bolsa, donde la mayor parte de los avecindados no tenían un aval, se establecían las rentas a corto plazo a precios relativamente altos". ${ }^{57}$ Ahora bien, en la medida en que las viviendas no tenían alumbrado, el uso del carbón podía servir como combustible y alumbrado y es posible que este fuera utilizado para cocinar los alimentos, para calentar las tortillas o para otros usos afines a las necesidades de las trabajadoras ya que utilizaban carbón y petróleo.

En cuanto a las medidas de higiene y limpieza personal, es preciso apuntar que de los ejemplos expuestos solo Antonia Delgadillo destinaba de su ingreso lo correspondiente al aseo (16,6\%). Empero, es posible deducir que este gasto podía incluir tanto jabón como baño. Para el caso de la costurera Valihache, quien no consumía ese aspecto, pudo haber sido parte de la clientela que asistía a los baños públicos ubicados en varios puntos de la capital mexicana, entre los más frecuentes se asistía a los baños Juárez. Sin embargo, en la medida en que no reportó desembolsar parte de su sueldo para tal rubro se puede inferir que los hábitos sanitarios se practicaban esporádicamente.

Como podemos ver en la ejemplificación de estas trabajadoras, un gasto que no era periódico en su costo de vida era el aseo. De acuerdo con Eliseo Garza, una familia de trabajadores gastaba diario de 0,04 a 0,10 centavos entre jabón y baño. ${ }^{58}$ Los factores que determinaron las estimaciones de Garza, con respecto al uso de jabón y aseo personal, fueron los reducidos salarios que los

56 AHCM, México, Ayuntamiento, vol. 3963, expediente 21.

57 AHCM, México, Ayuntamiento, vol. 3963, expediente 21.

58 Garza, Estudio sobre el costo, 15. 
trabajadores recibían los cuales no permitían satisfacer sus necesidades al respecto:

El aseo personal y lavado de ropa de cada uno de los miembros de la familia obrera objeto de este estudio, ha sido detenidamente considerado conforme a las necesidades imperiosas que muchas veces no pueden verse satisfechas, debido a la lucha constante que los trabajadores sostienen con sus reducidos salarios, más que por el abandono intelectual y moral tantas veces puesto de relieve en el programa evolutivo de las clases laborantes, y a fin de que nuestro cálculo al mismo tiempo que llene las exigencias de la familia, no resulte en ninguna forma exagerado. ${ }^{59}$

Aunado a ello, el inspector reportó que había distinciones de precios en los 32 baños públicos que tenía la Ciudad de México entre 1921 y 1922. Al respecto, menciona que en la capital había baños para obreros que ofrecían sus servicios a un costo de 10 y 20 centavos. No obstante, no menciona en qué parte de la ciudad estaban dichos establecimientos y por qué eran utilizados exclusivamente por los trabajadores más allá de que uno de los factores fuera el precio. Por el contrario, el inspector solo reportó que una familia obrera no podía tener acceso a este servicio porque sus ingresos diarios no excedían los 10 centavos. ${ }^{60} \mathrm{Si}$ se toma en cuenta el gasto de la tortillera, quien sí destinaba parte de sus ganancias al aseo, los promedios de Garza no se cumplen porque esta mujer gastaba 38 centavos diarios en cubrir las necesidades de aseo.

Como se puede apreciar, el estudio del gasto doméstico permite observar de qué manera las estimaciones socioeconómicas realizadas por las instancias de gobierno como el Departamento del Trabajo no se ajustaban a la realidad vivida por los trabajadores de la Ciudad de México. Si bien en este análisis solo utilicé el caso de dos mujeres que se dedicaban a oficios distintos, son una muestra representativa del resto de los sectores productivos. Más aún, con este instrumento contable pude analizar el nivel de vida propuesto y establecer que tanto la costurera como la tortillera eran parte de los sectores populares que vivían en la pobreza durante la reconstrucción del país de acuerdo con la ley de Engel, la cual estipulaba que entre mayor fuera el porcentaje destinado a la compra de alimentos más era el grado de pobreza y esto se puede comprobar con los presupuestos familiares de las tablas 3 y 5 .

59 Garza, Estudio sobre el costo, 12.

60 Garza, Estudio sobre el costo, 12. 


\section{Consideraciones finales}

Algunas anotaciones finales que tomé en cuenta parten de la utilidad metodológica que utilicé para estudiar a las trabajadoras de la Ciudad de México en el periodo posrevolucionario. Abordé el gasto doméstico como un indicador sensible para analizar los niveles de vida y así poder conocer los cambios económicos en la vida de las trabajadoras, "con miras [a apuntar] la desigualdad de la distribución del ingreso". ${ }^{61}$ Para ello, lo ajusté al contexto nacional y analicé los presupuestos mensuales de dos tipos de trabajo femenino que recibían ingresos mínimos, los cuales destinaban a satisfacer sus necesidades básicas: alimentarse, vestirse, alojarse y asearse.

Estas trabajadoras que vivieron la etapa posrevolucionaria en la Ciudad de México representaron un crecimiento -como apunta Leonardo Lomelí sobre la situación económica de 1921- "nulo, o bien, levemente positivo". ${ }^{62}$ Con los índices de salarios mínimos estimados por Aurora Gómez-Galvarriato y Aldo Musacchio identificamos que la canasta básica de estas trabajadoras pertenecía a un grupo o sector social con menores ingresos y que sus gastos alimentarios representaban más del $60 \%$ de sus percepciones. Lo cual, de acuerdo con la ley de Engel explicada en función del gasto en alimentos, indicaría que eran trabajadoras pobres y que efectivamente no podían sostener a su familia con lo que ganaban, aun cuando la costurera y la tortillera fueran jefas de hogar a cargo de la manutención de sus núcleos domésticos. Por tanto, en ocasiones empleaban estrategias de supervivencia solidarias como el obsequio de ropa, alimentos o cubrir el alquiler mediante la portería de la vecindad.

Con respecto a los patrones de consumo, se puede apreciar que tanto el pan como la carne y el pulque constituían los alimentos que formaban las experiencias alimenticias en común entre las trabajadoras. Después del proceso revolucionario el precio del pan, aunque era fluctuante, podía ser pagado por las trabajadoras y sus familias. En la década de los veinte, este alimento ya no representaba un indicador de jerarquía social, como sí lo fue en décadas anteriores, y se alejaba de ser un lujo alimenticio. No obstante, cabe resaltar que tanto la tortillera Antonia Delgadillo como la costurera Ángela Valihache bebían cantidades considerables de pulque y leche, lo cual hace pensar que se ingerían en el almuerzo, comida y merienda.

61 Levi, "Escala de análisis", 115.

62 Leonardo Lomelí Vanegas, "La recuperación económica y su impacto en el centro del país durante el gobierno de Álvaro Obregón”, Economía, sociedad y territorio (México: El Colegio Mexiquense, 2004), 8. 
En ese sentido, las estimaciones calóricas de los especialistas en composición química y nutricional operaban solo como estándares estructurales que se alejaban de la experiencia de vida de las clases populares de la capital. Por tanto, no solo fomentaban la segregación por patrones de consumo alimenticio y dietas tradicionales, sino que fomentaban la división social, jerarquía laboral y explotación de mano de obra, invisibilizando las agencias de los trabajadores con oficios distintos, como la tortillera y costurera insertas en una economía local de la capital mexicana.

Ante ello, pude constatar que los índices generales de precios, así como los estudios estadísticos ofrecidos desde la macroeconomía del periodo estudiado, omiten las reducciones de escala en las condiciones de vida de los trabajadores y de su gasto doméstico. Más aún, plasman visiones triunfalistas y equívocas que no se reflejan a nivel de individuos de bajos ingresos como las trabajadoras analizadas en este artículo. 
Title: For What It Can Afford! Domestic Expenses of Female Workers in Mexico City, 1917-1921

Abstract: This article focuses on the household expenses of a seamstress who made clothes at home and a woman who cooked tortillas. It aims to study the living conditions of these workers after the Mexican Revolution, to understand the impact of this armed process on their homes. In order to do so, it considers the conformation of their basic baskets, based on the relationship between their income and the prices products and services such as food, rent, clothing, fuel and cleaning. The paper draws upon surveys on the cost of living prepared by the Labor Department during 1921. It points out that female workers subsisted on limited budgets, which indicates that hardly any of them had enough to live.

Keywords: female workers, household expenses, basic food basket, Mexico City.

Título: Pelo que alcança! Os gastos domésticos das trabalhadoras na Cidade do México, 1917-1921

Resumo: O artigo estuda as despesas domésticas de uma costureira que fazia roupas em casa e de uma mulher que fazia tortilhas. O objetivo é conhecer as condições de vida dessas trabalhadoras após a Revolução Mexicana, a fim de saber como esse processo armado as impactou em suas casas. Para constatar, a conformação de suas cestas básicas foi levada em conta a partir da relação entre sua renda e os preços de bens de primeira necessidade como alimentação, aluguel, roupas, combustível e limpeza. Este estudo foi realizado a partir de levantamentos de custo de vida no trabalho elaborados pelo Ministério do Trabalho durante o ano de 1921. É importante mencionar que a partir desse instrumento contábil se constatou que as trabalhadoras viviam com orçamentos limitados, o que indica que quase não possuíam o suficiente para viver.

Palavras-chave: trabalhadoras, gastos familiares, cesta básica, Cidade do México 